\title{
Study of Accident Progression in Unsealed WWER-1000/V320 Reactor during Maintenance
}

\author{
Pavlin Groudev, Marina Andreeva \\ Institute for Nuclear Research and Nuclear Energy-Bulgarian Academy of Sciences, Sofia, Bulgaria \\ Email: m_andreeva@inrne.bas.bg
}

Received 13 July 2016; accepted 26 August 2016; published 29 August 2016

Copyright (C) 2016 by authors and Scientific Research Publishing Inc.

This work is licensed under the Creative Commons Attribution International License (CC BY).

http://creativecommons.org/licenses/by/4.0/

(c) (i) Open Access

\begin{abstract}
This paper discusses the results obtained during an investigation of WWER-1000 Nuclear Power Plant (NPP) behavior at shutdown reactor during maintenance. For the purpose of the analysis is selected a plant operating state with unsealed primary circuit by removing the MCP head. The reference nuclear power plant is Unit 6 at Kozloduy NPP (KNPP) site. RELAP5/ MOD3.2 computer code has been used to simulate the transient for WWER-1000/V320 NPP model. A model of WWER-1000 based on Unit 6 of KNPP has been developed for the RELAP5/MOD3.2 code at the Institute for Nuclear Research and Nuclear Energy-Bulgarian Academy of Sciences (INRNE-BAS), Sofia. The plant modifications performed in frame of modernization program have been taken into account for the investigated conditions for the unsealed primary circuit. The most specific in this analysis compared to the analyses of NPP accidents at full power is the unavailability of some important safety systems. For the purpose of the present investigation two scenarios have been studied, involving a different number of safety systems with and without operator actions. The selected initiating event and scenarios are used in support of analytical validation of Emergency Operating Procedures (EOP) at low power and they are based on the suggestions of leading KNPP experts and are important in support of analytical validation of EOP at low power.
\end{abstract}

\section{Keywords}

Nuclear Power Plant Safety, RELAP5/MOD3.2 Computer Code, Unsealed WWER Type Reactor, Residual Heat Removal System, Low Power and Cold Conditions

\section{Introduction}

A number of events at nuclear power plants (NPP), as well as results from probabilistic safety assessment (PSA)

How to cite this paper: Groudev, P. and Andreeva, M. (2016) Study of Accident Progression in Unsealed WWER-1000/V320 Reactor during Maintenance. Journal of Power and Energy Engineering, 4, 68-78.

http://dx.doi.org/10.4236/ipee.2016.48007 
studies for NPPs, have indicated that events occurring during shutdown modes may contribute significantly to the overall risk associated with NPP operation. Events occurring during shutdown operational modes represent a significant contribution to the NPP risk due to the fact that both preventive and mitigative capabilities of the plant can be degraded [1]. According to [2] deterministic analyses should be performed for transients that can occur in all planned modes of the plant in normal operation, including operations during shutdown. This plant state was sometimes neglected in early safety analyses. For this mode of operation, the contributors to risk include: the inability to start some safety systems automatically; equipment in maintenance or in repair; reduced amounts of coolant in the primary circuit as well as in the secondary circuit for some modes; instrumentation switched off or non-functional and measurements not made; open primary circuit; and open containment. Every configuration of shutdown modes should be analysed.

In Bulgaria, the main regulatory requirements related to the safety analysis for NPP are specified by the Bulgarian nuclear legislation [3]. The regulation requires that NPP safety analysis shall be included all various plant conditions and operator actions at all modes of operation. In this paper are presented the results obtained during an investigation of WWER-1000 NPP behaviour at shutdown reactor during maintenance as following international and national requirements in nuclear safety. In the paper are presents a thermal-hydraulic analysis of residual heat removal (RHR) system failure due to loss of low pressure pump (LPP) connected in RHR mode. The selected plant state requires draining of the primary circuit coolant to the level of upper part of the MCP vessel.

The purpose of the analysis is to define the timing for reaching the following stages during the development of processes in the reactor system:

- Loss of subcooling $(\Delta \mathrm{TSI}<10 \mathrm{~K})$ in the core outlet;

- Beginning of reactor core uncovery;

- Beginning of primary circuit cold legs uncovery;

- Beginning of core outlet temperature increase;

- The fuel cladding temperature beyond $923.15 \mathrm{~K}$;

- Estimation of time for operators' intervention.

The selected plant operating state is maintenance work with unsealed primary circuit by removing the MCP head. The need of such analyses is determined by requirements for validation of EOP at shutdown and low power.

\section{Description of the KNPP and Relap5 Model}

The reference power plant for this analysis is Unit 6 at KNPP site. Systems and equipment of the KNPP, Unit 6 operate according to the design requirements for the corresponding level of reactor power [4].

The RELAP code is designed to predict the behavior of reactor systems during normal and accident conditions [5]. The analysis of the nuclear power plant's behavior with thermo-hydraulic code is carried out for its safety justification in case of design disturbances during the processes and malfunctions or failures of the equipment. Several studies related to the WWER-1000 nuclear power plant accident, have been modeled with RELAP5/MOD3.2 [6]-[11]. Most of the publications present accident analyses in the full power operation of the plant. Nowadays nuclear safety regulations require the shutdown state to be more systematically analyzed. In the present paper a transient in shutdown state of the plant is analysed. For the purpose of the paper RELAP5/ MOD3.2 computer code has been used to simulate the WWER-1000/V320 NPP model [12]. The model has been developed at INRNE-BAS for the analyses of operational occurrences, abnormal events, and design basis scenarios. The RELAP5 nodalization schemes of the plant used in the analysis are presented in Figures 1-4. In modifying of the RELAP5 input data describing the model of the reactor WWER-1000 the shutdown and cold conditions and the modifications after the modernization program are taken into account. The actual four-loop system has been modelled by four single loops for primary and secondary sides. The model provides a significant analytical capability for the specialists working in the field of NPP safety. In the RELAP5 model for WWER-1000/V320 NPP included are as follows: Reactor vessel; core region represented by three channels; pressurizer system including heaters, spray and relief valves; safety system-low pressure injection pumps. In the model, also presented is a make-up/drain system, including a connection (control) with the pressurizer. Secondary side is developed too and is presented by eight SG Safety valves, four BRU-A valves, BRU-K valves, steam pipe lines (including main steam header) and turbine, including a regulating valve in front of the turbine. The horizontal steam generator (SG) has been modelled. A separator model and the perforated sheet have been modelled in the SG model too. The MCP has been developed using homologous curves of real pumps. 




Figure 1. RELAP5 nodalization scheme of KNPP reactor and pressurizer.

\section{Initial and Boundary Conditions}

The reactor is at shutdown and cold condition before outage. The primary circuit is opened by removing MCP heads for performing some maintenance actions. Primary circuit water level is reduced to the upper part of MCP vessel. All control rods are inside the reactor core. Boron concentration is at $16 \mathrm{~g} / \mathrm{kg}$. One channel of LowPressure Safety Injection System (LPSIS) is on standby. All other characteristics are selected as boundary conditions. The steady-state RELAP5 model for WWER-1000 reactor is presented in Table 1.

Specific assumptions

All systems for normal operation is are unavailable after the initiating event. According to [3], it is assumed that the operator switches on an LPSIS 30 min after the beginning of the event.

In investigating conditions the safety systems are in following modes:

- one channel of LPSIS is in residual heat removal mode; 


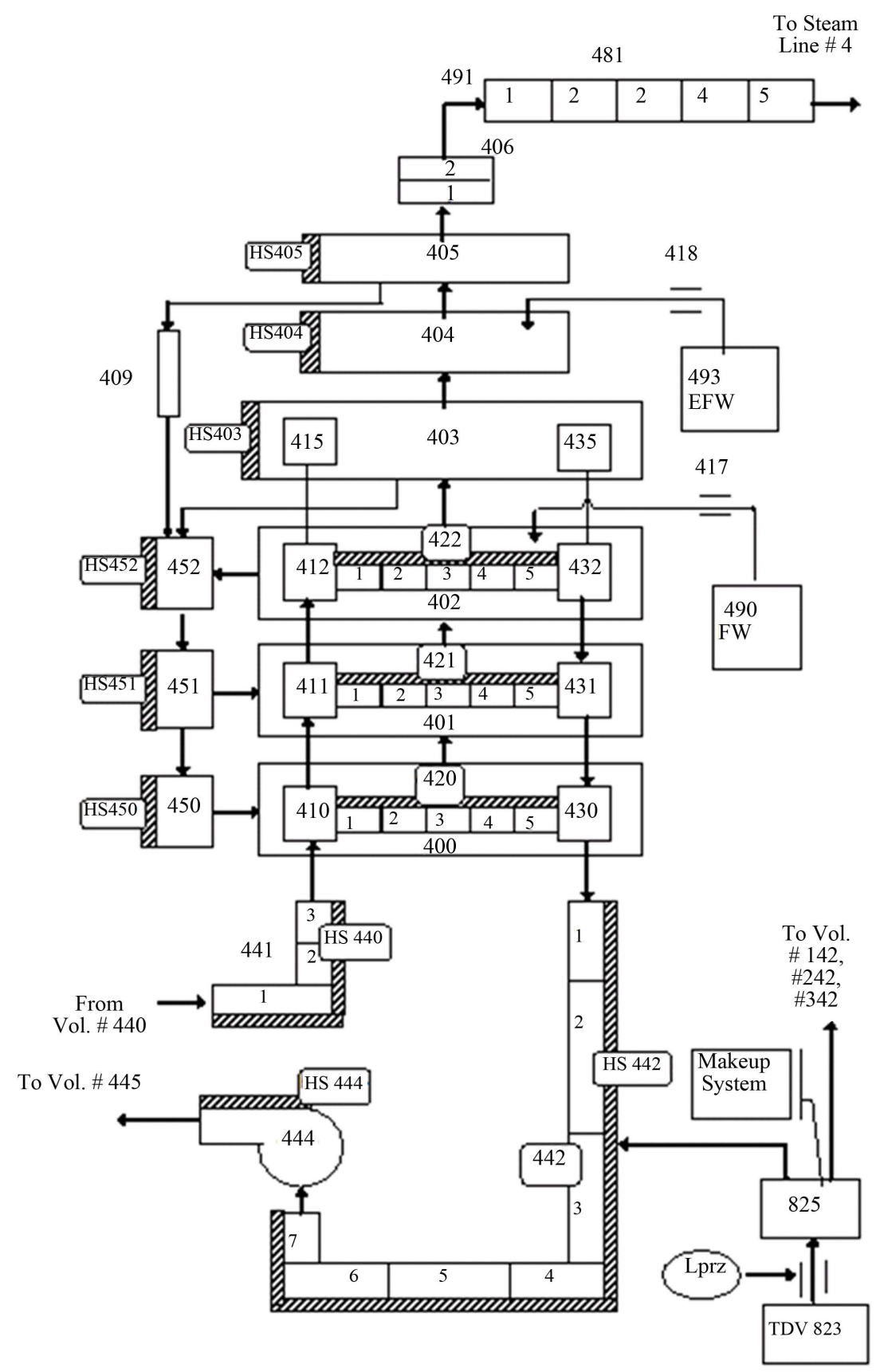

Figure 2. RELAP 5 nodalization scheme of KNPP steam generator.

- the second channel of LPSIS is connected by emergency make-up tank;

- the third channel of LPSIS is consider to be under maintenance.

Primary make-up system is conservatively excluded in the model.

\section{Simulated Accident Scenarios}

The scenario was discussed with KNPP experts as the most reasonable from an engineering point of view. In this way it can be stated that the scenarios are prepared based on engineering judgment and experience of the authors in analysis plant events.

The purpose of the analysis is to determine the development of the accident and to evaluate the time the oper- 


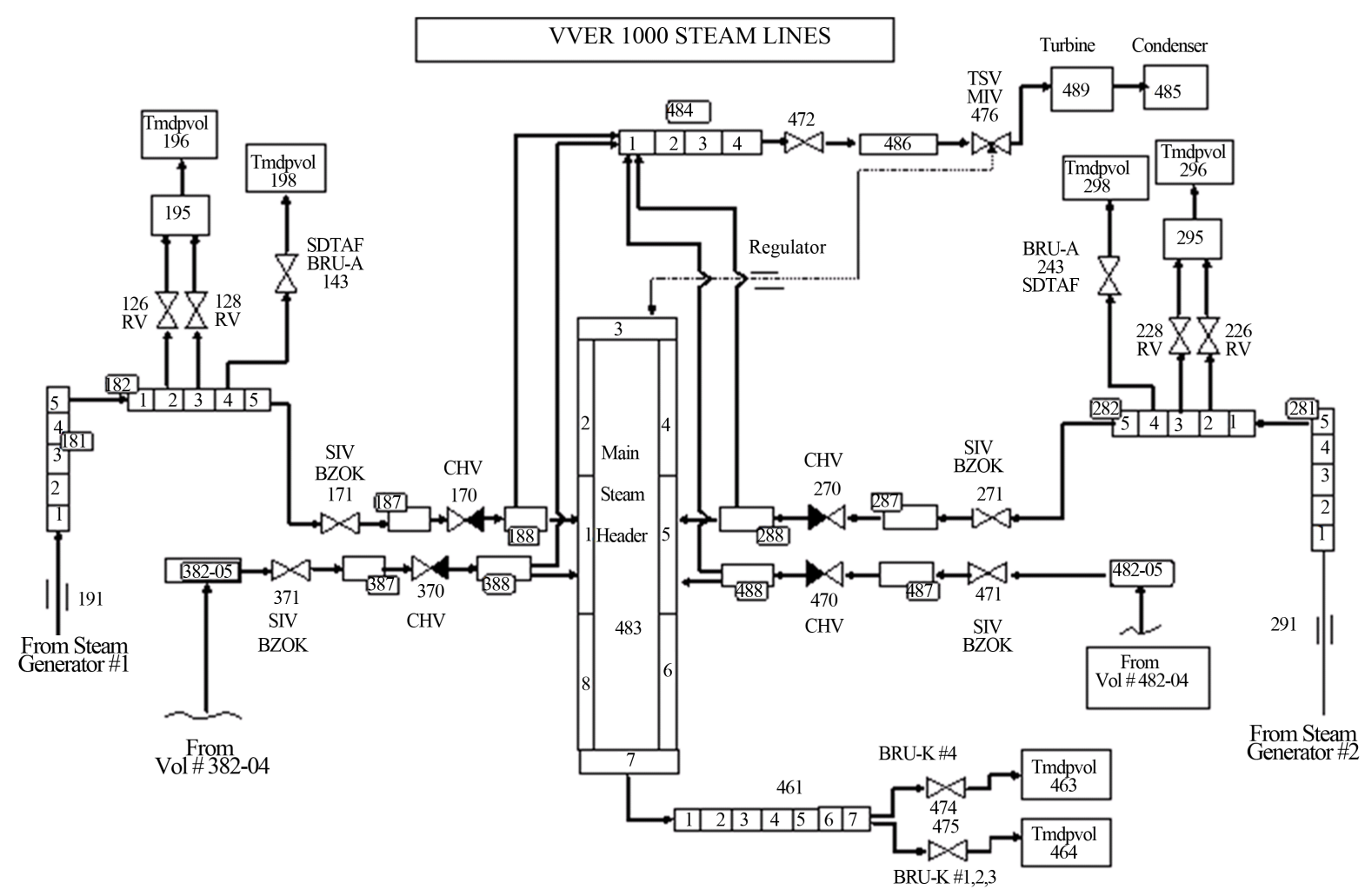

Figure 3. RELAP 5-nodalization scheme of KNPP steam lines.

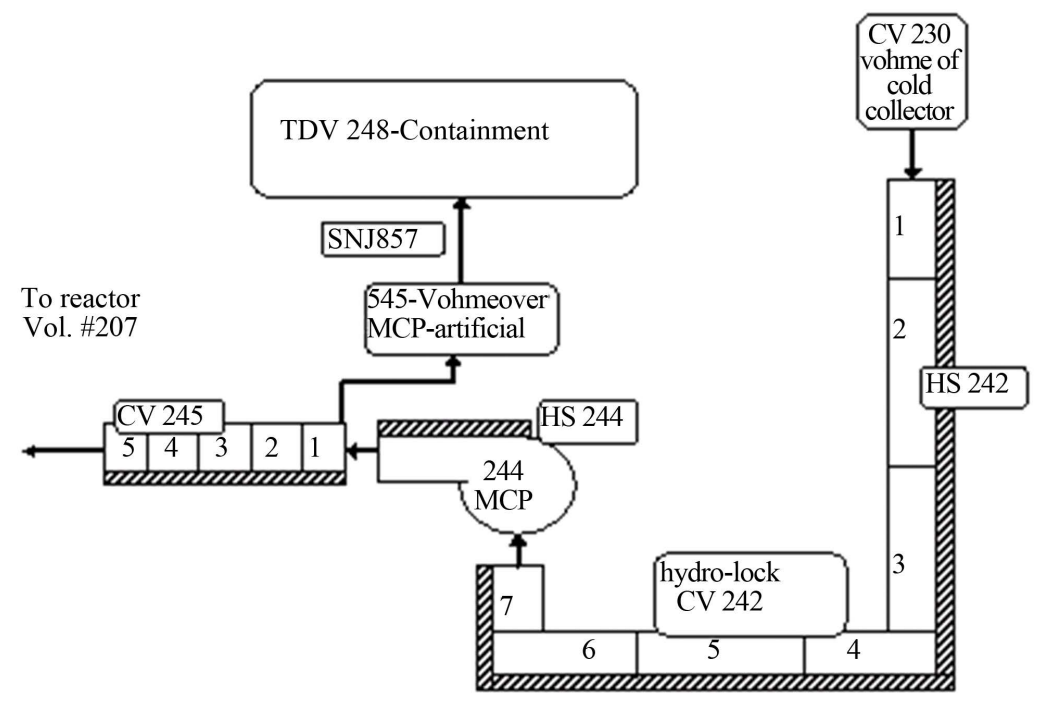

Figure 4. Nodalization scheme of unsealed primary circuit.

ators from main control room (MCR) have before taking the necessary actions to prevent core damage in cases where this time is under 30 minutes.

\subsection{Base Case Scenario}

Without operator actions: The main goal of the analysis is to determine the progress of the accident and to assess the time which operators from MCR have before taking the necessary action to prevent core damage, where this time is less than $30 \min [3]$. 
Table 1. Main parameters of the steady-state RELAP model.

\begin{tabular}{cc}
\hline Plant parameters & Plant value \\
\hline Plant power state & $0 \%$ (shut down) \\
Subcritical reactor state & $\geq 2 \%$ \\
Residual heat & $11.5 \mathrm{MW}$ \\
Primary pressure & atmospheric \\
Core inlet temperature & T = 343.15 K \\
Reactor coolant level & Correspond to the level of upper part to the MCP vessel or lower. \\
Pressurizer water level & (it is assumed 0/20/0/35 m below the level of upper part to the MCP vessel. \\
SG water level & 2/8 m (it is determined by the water level in the MCP vessel, which is un- \\
Boundary conditions & sealed and LPSIP flow to the hot leg) \\
HPSIS tank temperature & Dry out \\
Emergency make-up tank temperature & Value \\
Technical water flow rate through heat exchangers & $333.15 \mathrm{~K}$ \\
Service water temperature inlet of the heat exchangers & $333.15 \mathrm{~K}$ \\
Emergency make-up tank level & $2800 \mathrm{~m}{ }^{3} / \mathrm{h}$ \\
Hydro accumulators temperature & $306.15 \mathrm{~K}$ \\
Hydro accumulators pressure & $3.1 \mathrm{~cm}$ \\
LPP flow rate & $333.15 \mathrm{~K}$ \\
\hline
\end{tabular}

\section{The expected accident scenario:}

1) Initiating event-LPSIS failure in $0.0 \mathrm{~s}$;

2) Simulation of failure of protection signal $Y Z$ which was actuated due to $\Delta T_{\mathrm{SI}}<10^{\circ} \mathrm{K}$. Because of that all channels of LPSIS are failed. YZ signal controls safety system;

3) Core uncovery;

4) The fuel cladding temperature beyond $923.15 \mathrm{~K}$.

\subsection{Operator Actions Scenario}

The main objective of the analysis is to demonstrate the effectiveness of the operator's action, in which the acceptance criteria "non-uncovering reactor core" has been successfully implemented.

\section{The expected accident scenario:}

1) Initiating event-LPSIS failure in $0.0 \mathrm{~s}$;

2) Simulation of failure of protection signal $\mathrm{YZ}$ which was actuated due to $\Delta \mathrm{T}_{\mathrm{SI}}<10 \mathrm{~K}$. Because of that all channels of LPSIS are failed. YZ signal controls safety system;

3) The operator starts one LPP after $\Delta \mathrm{T}_{\mathrm{SI}}<10^{\circ} \mathrm{K}$ and $30 \mathrm{~min}$ after the beginning of event. Operation scheme is:

Safety injection tank (sump)—LPSIS emergency tank—LPP—Primary circuit—Containment—Safety injection tank (sump).

\section{Results and Discussions}

The calculated sequence of events for the base case and operator action scenarios are presented in Table 2. Comparisons of the most important parameters' behaviour for the two scenarios are shown in Figures 5-12. The calculations are performed up to $15,500 \mathrm{~s}$ into transient time for the base case and up to $6000 \mathrm{~s}$ for the operator action scenario.

As a result of the LPP failure the water temperature starts to increase, leading to an increase in the coolant volume due to a change in the density of water, and after about $396 \mathrm{~s}$ is observed filling volume which simulates 


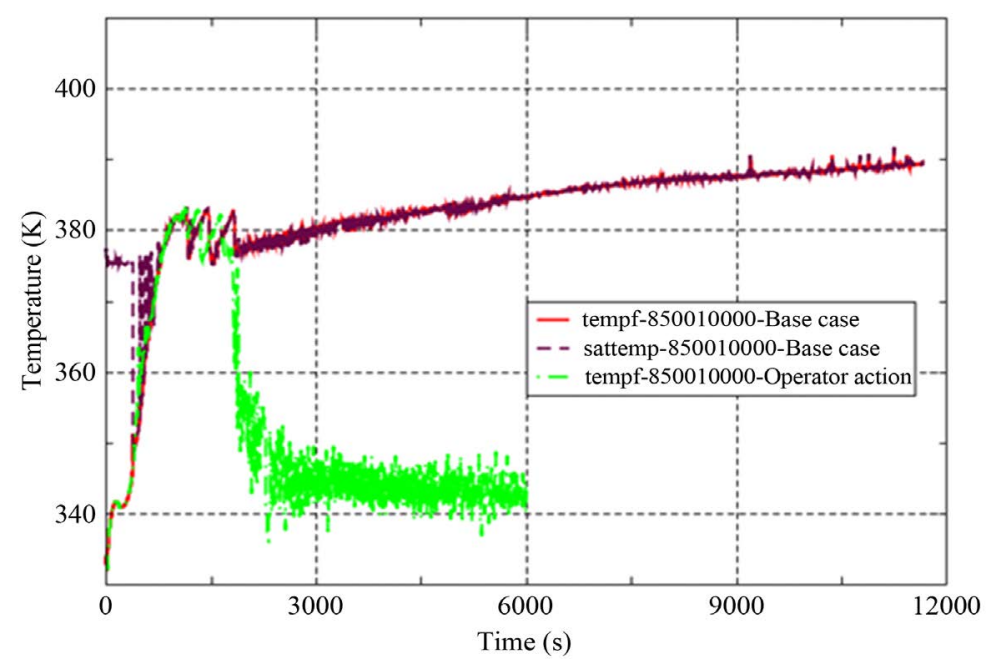

Figure 5. Core outlet temperatures.

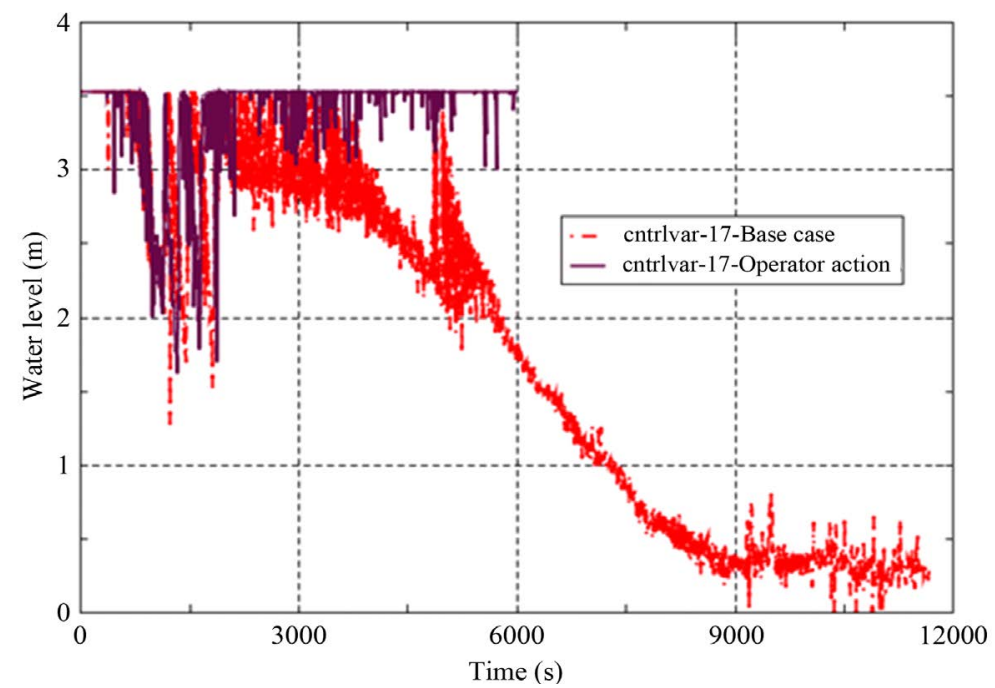

Figure 6. Water level in the reactor core.

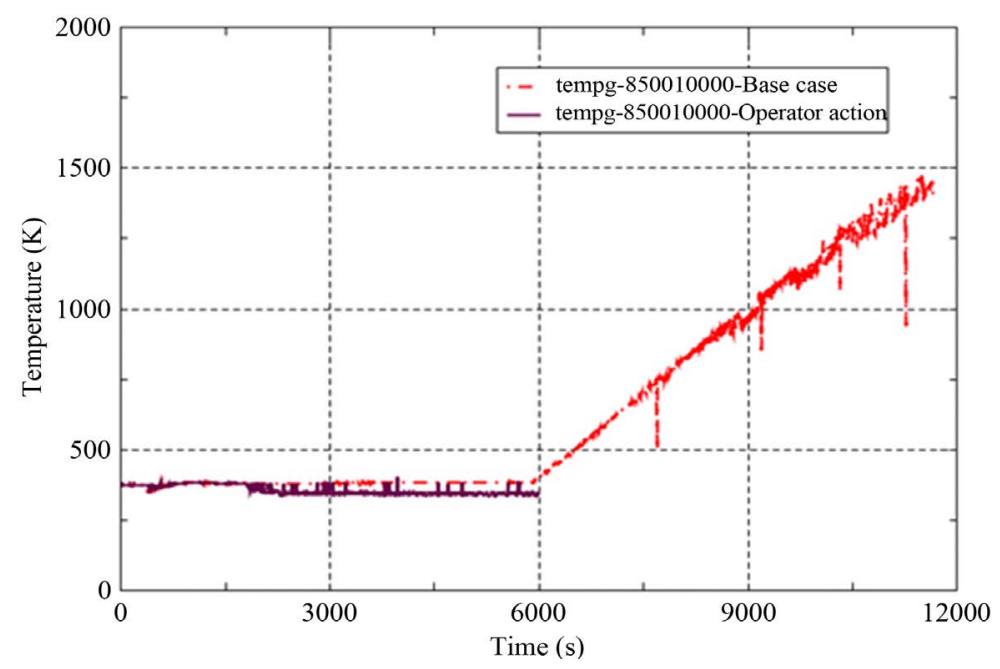

Figure 7. Gas coolant temperature in the core outlet. 


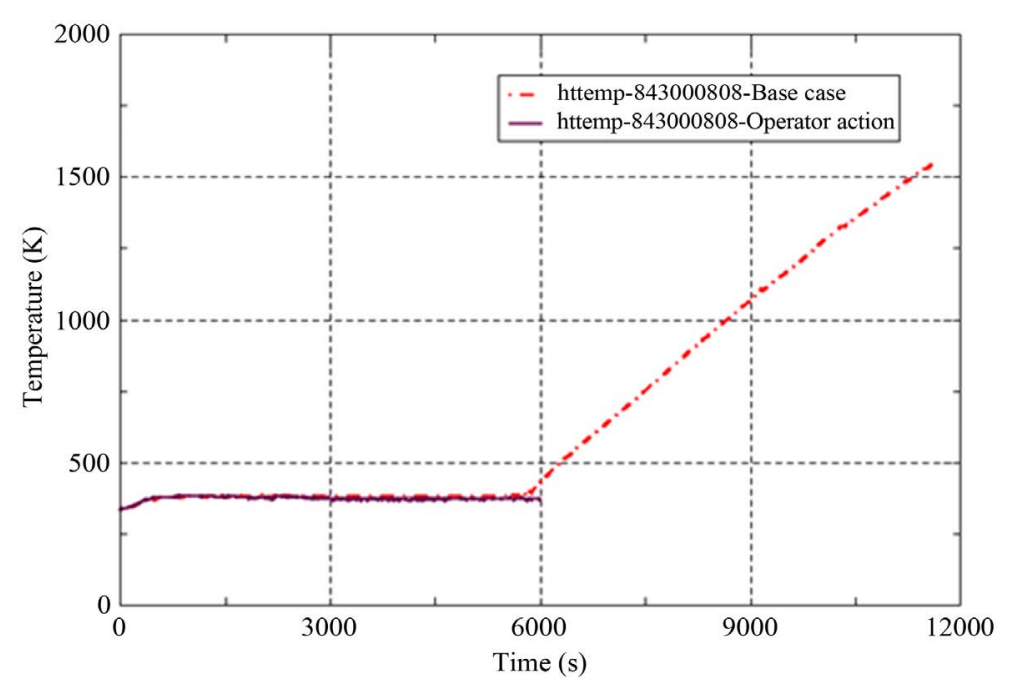

Figure 8. Fuel cladding temperature in the core.

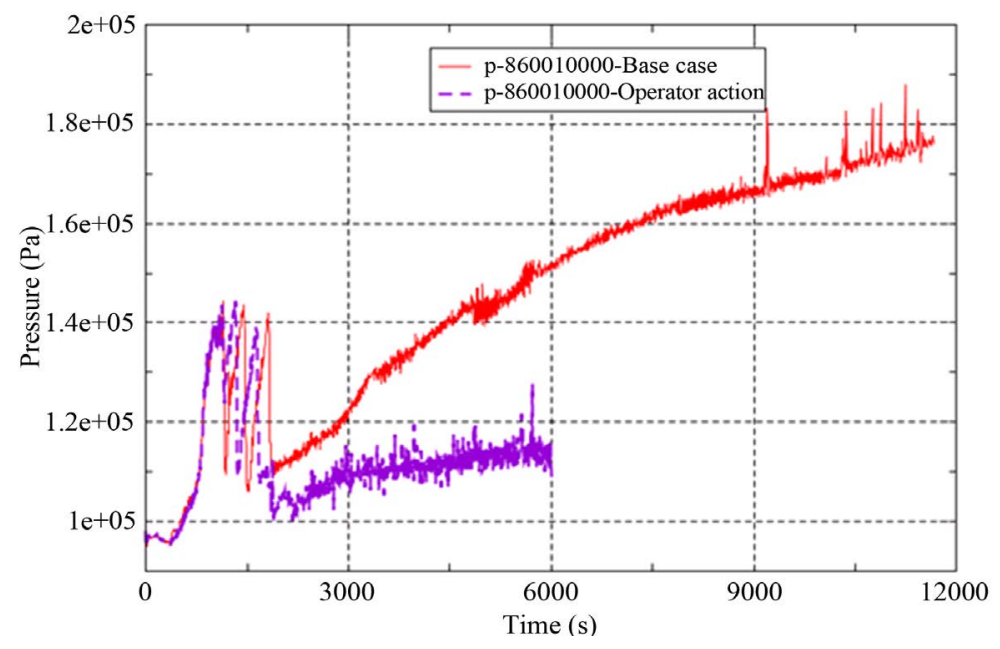

Figure 9. Primary pressure.

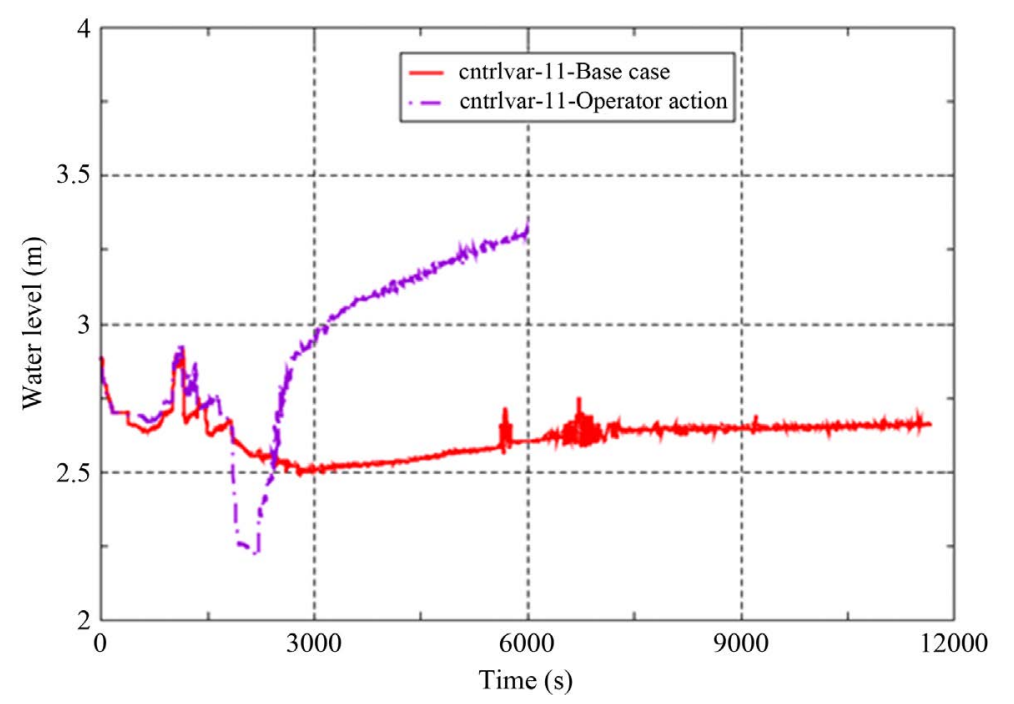

Figure 10. PRZ level. 


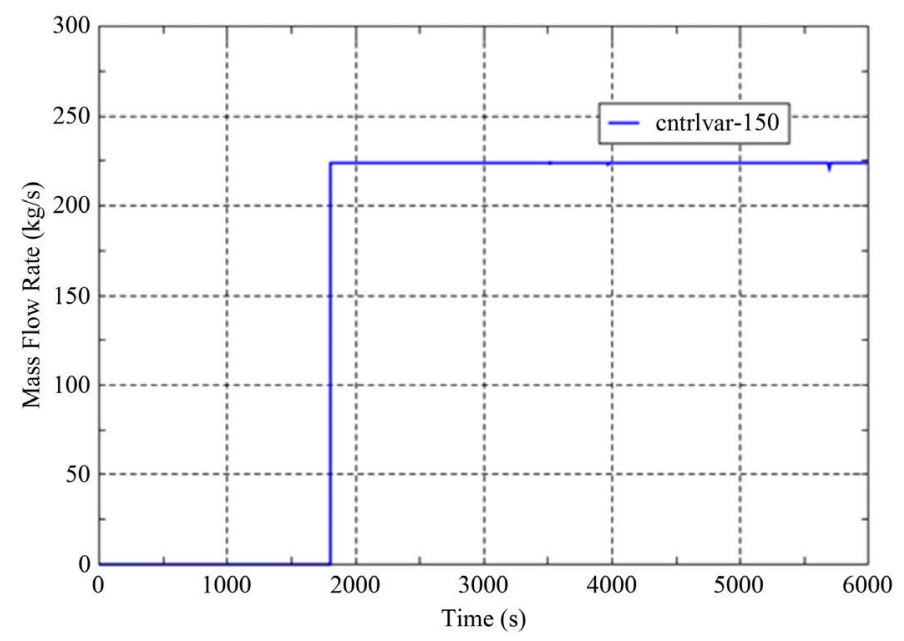

Figure 11. LPP flow rate to primary circuit-operator action.

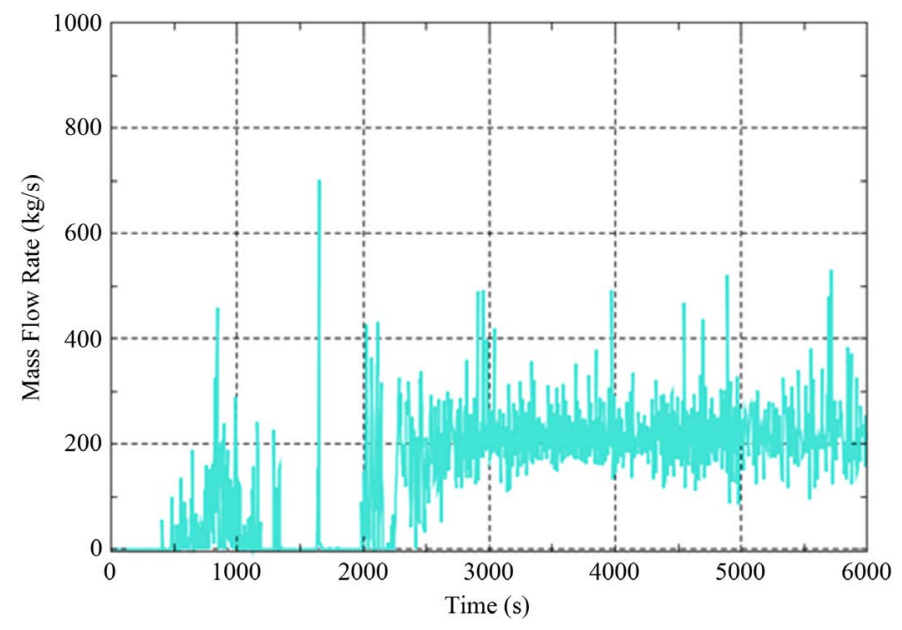

Figure 12. Leakage flow rate through unsealed MCP to containmentoperator action.

Table 2. Calculated sequence of events for base case and operator action scenarios.

\begin{tabular}{|c|c|c|}
\hline \multirow{2}{*}{ Event } & Basecase & Operator action \\
\hline & Time, $s$ & Time, $s$ \\
\hline LPSIS failure & 0.0 & 0.0 \\
\hline Beginning uncovery of primary circuit hot legs & 0.0 & 0.0 \\
\hline Loss of subcooling $\left(\Delta \mathrm{T}_{\mathrm{SI}}<10 \mathrm{~K}\right)$ in the core outlet & 390 & 390 \\
\hline Actuation of LPSIS & No & No \\
\hline $\begin{array}{c}\text { Beginning of coolant leakage through the upper part of MCP depressurized due to coolant } \\
\text { overheating and thereby increase its volume }\end{array}$ & 396 & 396 \\
\hline Beginning core uncovery & 723 & 723 \\
\hline Beginning uncovery of primary circuit cold legs & 1142 & 1142 \\
\hline Operator starts LPP & - & 1800 \\
\hline Total uncovery of primary circuit cold legs & 3503 & N/A \\
\hline Beginning core outlet temperature increasing & 5951 & N/A \\
\hline The fuel cladding temperature beyond $923.15 \mathrm{~K}$ & 8243 & N/A \\
\hline End of calculation & 15,500 & 6000 \\
\hline
\end{tabular}


the upper part top of the unsealed MCP and there is significant loss of coolant, which stops at $1400 \mathrm{~s}$ as a result of evaporation of water, which boils at $390 \mathrm{~s}$. Thus the loss of coolant up to $1400 \mathrm{~s}$ is as the leakage at initial moment (due to coolant expansion), and the evaporation of coolant through unsealed MCP. Loss of subcooling (boiling of the coolant) in the core outlet is shown in Figure 5.

The behavior of the water level in the reactor core for the both scenarios is shown in Figure 6. After discontinue of the decay heat from the reactor core through an LPP it starts coolant reheating and therefore small water over the core, it quickly reaches boiling point. This is supported by both the increase of the temperature for the first $390 \mathrm{~s}$ (reaches $100^{\circ} \mathrm{C}$ ) and the rapid loss of the water level above the core, which for this type of accident is below the level of the primary circuit hot legs. One of the characteristics of this accident is that the reactor coolant level is 0.20/0.35 m under upper part of the MCP vessel. Although the residual heat is less (11.5 MW), by Figure 6 shows how fast (after 723 seconds-see Table 2) the core begins to uncover. Uncovering the core is the result of boiling water at the core outlet. Thus for base case, after about $3503 \mathrm{~s}$, when the primary circuit cold legs uncover, the reactor core is cooling only by the water which is in the reactor vessel and has already begun the uncovering of the upper end of the core. Due to the boiling of the coolant at a pressure close to atmospheric, with slight changes, the low decay heat, for a long time no rise in temperature of the fluid is observed, i.e. no core heating is observed, which eventually occurs after significant core uncovery at $5951 \mathrm{~s}$. At $8243 \mathrm{~s}$ fuel cladding temperature of the core outlet reaches $923.15 \mathrm{~K}$, which is a condition for leaving SB EOP and transition to SAMG.

Fluid heat up over the reactor core is shown in Figure 7, using the steam temperature because in RELAP5 the liquid temperature reaches only a saturation temperature, which depends only on pressure-i.e. steam is overheated. For base case after $5951 \mathrm{~s}$ begins core reheating and there is overheated steam over the reactor core (Figure 6).

For the scenario with operator action it is assumed that 30 minutes after the beginning of the accident, the operator actuates one LPP. As a result of operator actions is prevents overheating of reactor core and coolant.

The fuel cladding temperatures are presented on Figure 8. For base case the fuel cladding temperatures have increased with the beginning of the core uncovery and at $8243 \mathrm{~s}$ have reached the boundary value $-923.15 \mathrm{~K}$ of transition between EOPs and SAMG. For operator action scenario the fuel cladding temperatures do not reach this boundary value.

The behavior of the primary pressure is shown in Figure 9. Initially the pressure is about atmospheric, and slightly increases up to about less than 2 atmospheres due to boil water in the core and in the presence of hydro-lock in primary circuit cold leg, which do not allow free movement of the steam to the point of the primary circuit depressurization - upper part of the MCP\#2. The pressurizer (PRZ) level is presented in Figure 10. LPSIP flow rate is presented in Figure 11, Figure 12 illustrated leakage flow rate through unsealed MCP to containment.

\section{Conclusions}

In the paper is discussed the thermal-hydraulic calculation of loss of RHR system at shut down plant state and unsealed primary circuit for WWER-1000/V320 units at KNPP. As a result of the thermo-hydraulic analysis the following general conclusions are formulated:

The operator has a short time to avoid a partial core uncovery. The reason is the minimum coolant volume in the primary circuit and unavailability of secondary side. The partial core uncovery, which is observed in the first 10 - 30 minutes, does not lead to the core heating up, due to low residual power for this plant state.

Simultaneously, it should be noted that due to the characteristic of the initial state, namely atmospheric pressure and an inlet temperature of the core $343.15 \mathrm{~K}$ and minimum residual heat, beginning of reactor core heat up occurs after $5950 \mathrm{~s}$, thefuel cladding temperature reached the $923.15 \mathrm{~K}$ (boundary value of transition between EOPs and SAMG) at $8243 \mathrm{~s}$. This shows that even if there is an insignificant core uncovery, the operator will have enough time for organizing of alternative core cooling before reactor core heat up occurs.

\section{References}

[1] IAEA (1998) Safety Analysis of Nuclear Power Plants during Low Power and Shutdown Conditions. IAEA-TECDOC1042.

[2] IAEA (2009) Deterministic Safety Analysis for Nuclear Power Plants. Specific Safety Guide No. SSG-2. 
[3] BNRA—Bulgarian Nuclear Regulatory Agency (2004) Statute Book on the Safe Use of Nuclear Energy, Vol. 1, Sofia.

[4] Groudev, P.P., Pavlova, M.P. and Demerdjiev, P.A. (1999) Data Base for VVER-1000/V320. SACI of KNPP, BOA 278065-A-R4, INRNE-BAS, Sofia.

[5] Allison, C.M. and Hohorst, J.K. (2010) Role of Relap/SCDAPSIM in Nuclear Safety. Science and Technology of Nuclear Installations, 2010, Article ID: 425658. http://dx.doi.org/10.1155/2010/425658

[6] Pavlova, M., Andreeva, M. and Groudev, P. (2015) Steam Line Break Investigation at Full Power Reactor for VVER-1000/V320. Nuclear Engineering and Design, 285, 65-74. http://dx.doi.org/10.1016/j.nucengdes.2015.01.006

[7] Pavlova, M., Andreeva, M. and Groudev, P. (2007) RELAP5/MOD3.2 Blackout Investigation for Validation of EOPs for KNPP VVER-1000/V320. Progress in Nuclear Energy, 49, 409-427. http://dx.doi.org/10.1016/j.pnucene.2007.06.001

[8] Andreeva, M., Groudev, P. and Pavlova, M. (2015) Analytical Validation of Operator Actions in Case of Primary to Secondary Leakage for VVER-1000/V320. Nuclear Engineering and Design, 295, 479-488. http://dx.doi.org/10.1016/j.nucengdes.2015.10.024

[9] Andreeva, M., Pavlova, M. and Groudev, P. (2012) Investigation of Critical Safety Function "Heat Sink" at Low Power and Cold Condition for Kozloduy Nuclear Power Plant WWER-1000/V320. Annals of Nuclear Energy, 40, 221-228. http://dx.doi.org/10.1016/j.anucene.2011.10.012

[10] Groudev, P., Andreeva, M. and Pavlova, M. (2013) Investigation of Nuclear Power Plant Behaviour at Low Power and Cold Conditions during an Overpressurization in Primary Circuit. Annals of Nuclear Energy, 62, 231-241. http://dx.doi.org/10.1016/j.anucene.2013.06.026

[11] Groudev, P., Andreeva, M. and Pavlova, M. (2015) Investigation of Main Coolant Pump Trip Problem in Case of SB LOCA for Kozloduy Nuclear Power Plant, WWER-440/V230. Nuclear Engineering and Design, 76, 137-145. http://dx.doi.org/10.1016/j.anucene.2014.09.050

[12] Groudev, P.P., Pavlova, M.P. and Demerdjiev, P.A. (1999) Engineering Handbook. SACI of KNPP, BOA 278065-AR4, INRNE-BAS, Sofia.

\section{Submit or recommend next manuscript to SCIRP and we will provide best service for you:}

Accepting pre-submission inquiries through Email, Facebook, LinkedIn, Twitter, etc.

A wide selection of journals (inclusive of 9 subjects, more than 200 journals)

Providing 24-hour high-quality service

User-friendly online submission system

Fair and swift peer-review system

Efficient typesetting and proofreading procedure

Display of the result of downloads and visits, as well as the number of cited articles

Maximum dissemination of your research work

Submit your manuscript at: http://papersubmission.scirp.org/ 